\title{
ARTICLE OPEN \\ In situ electrochemical dissolution of platinum and gold in organic-based solvent
}

\author{
Primož Jovanovič (iD), Vid Simon Šelih (iD) ${ }^{1}$, Martin Šala (iD) ${ }^{1}$ and Nejc Hodnik (iD ${ }^{2}$
}

In situ highly sensitive potential- and time-resolved monitoring of polycrystalline gold and platinum electrochemical dissolution in pure organic media is reported. This was achieved by successfully upgrading electrochemical flow cell coupled to inductively coupled plasma mass spectrometry. Similar to the aqueous media, aggressive transient dissolution takes place during oxide formation and reduction. In contrary to the aqueous electrolyte, both gold and platinum exhibit enhanced anodic compared to the cathodic oxide-assisted dissolution in organic media. This study intends to highlight the capabilities of the new methodology, which will expand the studies of metals dissolution to the fields like organic electrocatalysis, corrosion, battery research, and sensors among others.

npj Materials Degradation (2018)2:9; doi:10.1038/s41529-018-0031-8

\section{INTRODUCTION}

Understanding corrosion of metals is of pivotal importance due to the enormous abundance of metals in numerous applications. It is estimated that the corrosion is causing economical loss equal to $\sim 3 \%$ of the world's gross domestic product. ${ }^{1}$ It is intriguing that the noble metals were considered as corrosion resistant as they are used as protective layers against dissolution. Recent studies have shown that noble metals exhibit aggressive corrosion behavior. The driving force behind the increased understanding of noble metal electrochemical dissolution in recent years can mostly be attributed to the development of novel analytical approaches and techniques. Mayrhofer's group first introduced precise in situ dissolution studies of metals by successfully coupling the so-called scanning flow cell to an inductively coupled plasma mass spectrometer (ICP-MS). This allowed monitoring of the extremely low concentrations of dissolved metal in the downstream electrolyte. ${ }^{2-4}$ Effect of temperature, scan rate, dissolved gases, $\mathrm{pH}$, and impurities was carefully studied. Further developments of such approaches followed, e.g., Xing et al. ${ }^{5}$ used ion exchange chromatography coupled to ICP-MS to separate and detect Pt species generated by the electrodissolution of a Pt electrode. Following a similar concept as the one in Mayrhofer's group, our group developed the so-called electrochemical flow cell (EFC), also connected to ICP-MS for investigation of corrosion of nanoparticulate metallic composites. ${ }^{6-11}$ The latest use of ICP-MS analytics in an in situ mode was reported by Markovic's group where stationary probe rotating disk electrode was used to study the electrochemical stability of single crystal surfaces. ${ }^{12,13}$ On the topic of oxygen evolution also, Schlögl's group developed the similar methodology. ${ }^{14}$ Following in situ electrochemical dissolution of metals even without coupled techniques (e.g., EFC-ICP-MS) was also shown to be possible by using the so-called "channel double flow electrode" as reported by Shrestha et al. ${ }^{15}$ In spite of large contribution to the understanding of noble metal corrosion, these in situ analytics are limited to only aqueous electrolytes. This should be considered as a drawback since many relevant environments where metals are key components, such as capacitors, sensors, electrochemical reactors, and batteries operate in pure organic or a mixture of organic and aqueous phases. Furthermore, understanding the corrosion of noble metals has started to emerge as an important issue from the perspective of environmentally friendly recycling strategies, ${ }^{16}$ where organic solvents show much promise. ${ }^{17-20}$ ICPMS analysis of organic matrices is not as common as in case of aqueous matrices and presents a much greater challenge in tackling instrumental settings and several unusual spectral interferences. ${ }^{21}$ The presence of high levels of organic solvents increases the vapor pressure of the sample solution, which is circumvented by cooling the ICP-MS spray chamber to $-5^{\circ} \mathrm{C}$. This lowers the vapor pressure to the extent where stable plasma operation can be achieved. The other problem of high organic solvents in sample aerosol is the carbon (soot) deposition on the sampling cone, which can eventually lead to sampling cone orifice clogging. This is solved by oxidation reaction of carbon from the sample with oxygen. Therefore, when working with pure organic solvents, a small percentage of oxygen is added to the argon carrier gas. Our newly modified EFC-ICP-MS methodology reveals never before seen insights of potential-resolved platinum and gold dissolution in methanol. Dissolution of Pt and Au electrodes under electrochemical conditions were selected as these metals can be considered as the representatives of noble metals widely used in numerous electrochemistry applications. Dissolution of both metals in an in situ mode has been extensively studied before-either in the form of a polycrystalline disk ${ }^{22-24}$ or as a nanoparticulate composite. ${ }^{6,8,11,25-29}$ It has been shown that electrochemical dissolution is predominantly a transient phenomenon occurring due to the interplay of oxidation and reduction processes. In the anodic case, metals dissolve due to the formation of surface/subsurface oxides where oxygen and surface metal atoms undergo the so-called place exchange mechanism. ${ }^{30}$ In the

\footnotetext{
${ }^{1}$ Department of Analytical Chemistry, National Institute of Chemistry, Hajdrihova 19 SI-1000 Ljubljana, Slovenia and ${ }^{2}$ Department of Catalysis and Chemical Reaction Engineering, National Institute of Chemistry, Hajdrihova 19 SI-1000 Ljubljana, Slovenia

Correspondence: Vid Simon Šelih (vid.selih@ki.si) or Nejc Hodnik (nejc.hodnik@ki.si)
}

Received: 18 December 2017 Revised: 29 January 2018 Accepted: 4 February 2018

Published online: 21 March 2018 
case of cathodic dissolution, corrosion of metals is ascribed as a result of surface restructuring and roughening due to the reduction of oxides. ${ }^{2,23}$ These processes can be manipulated by changing the electrochemical treatment (scan rate, anodic, and cathodic potential window), gas atmosphere, and composition of aqueous electrolyte. ${ }^{6,8,22,31-34}$ For $\mathrm{Pt}$, the main dissolution mechanism at potentials above $1.2 \mathrm{~V}$ vs. reversible hydrogen electrode in an aqueous environment is the cathodic dissolution. ${ }^{23}$

This report intends to showcase highly sensitive in situ metal dissolution concentration potential- and time-resolved measurements in $100 \%$ organic solvent. We extended the capabilities of the EFC-ICP-MS to the organic solvents by modifying the conditions of ICP. Polycrystalline Au and Pt electrodes are shown to exhibit a change in their dissolution behavior.

\section{RESULTS}

Similar dissolution trend as in the previous works in the acidic and alkaline aqueous electrolytes ${ }^{24}$ is also observed in our case (Fig. 1 and S1.2), namely anodic dissolution (labeled as A) is less intense as the cathodic one (labeled as C). This is the first report on the dissolution of $\mathrm{Pt}$ in the $\mathrm{pH}$-neutral aqueous electrolyte; $0.1 \mathrm{~mol} / \mathrm{L}$ $\mathrm{NH}_{4} \mathrm{NO}_{3}$ aqueous solution. The same potentiodynamic experiment was performed in $0.1 \mathrm{M} \mathrm{NH}_{4} \mathrm{NO}_{3}$ methanol solution (Fig. 1b). Interestingly, the trend of $\mathrm{Pt}$ dissolution gets reversed with the anodic part exhibiting higher corrosion. We note that the listed water $(\mathrm{pKa}=15.7)$ and methanol $(\mathrm{pKa}=15.5)$ pKa values are similar. However, the pKa value for water was later shown to be 14 as predicted by thermodynamics. ${ }^{35}$ By this comparison, pure methanol is predicted to be less acidic than water. Nevertheless, both $0.1 \mathrm{M} \mathrm{NH}_{4} \mathrm{NO}_{3}$ electrolytes exhibit very similar $\mathrm{pH}$ conditions,
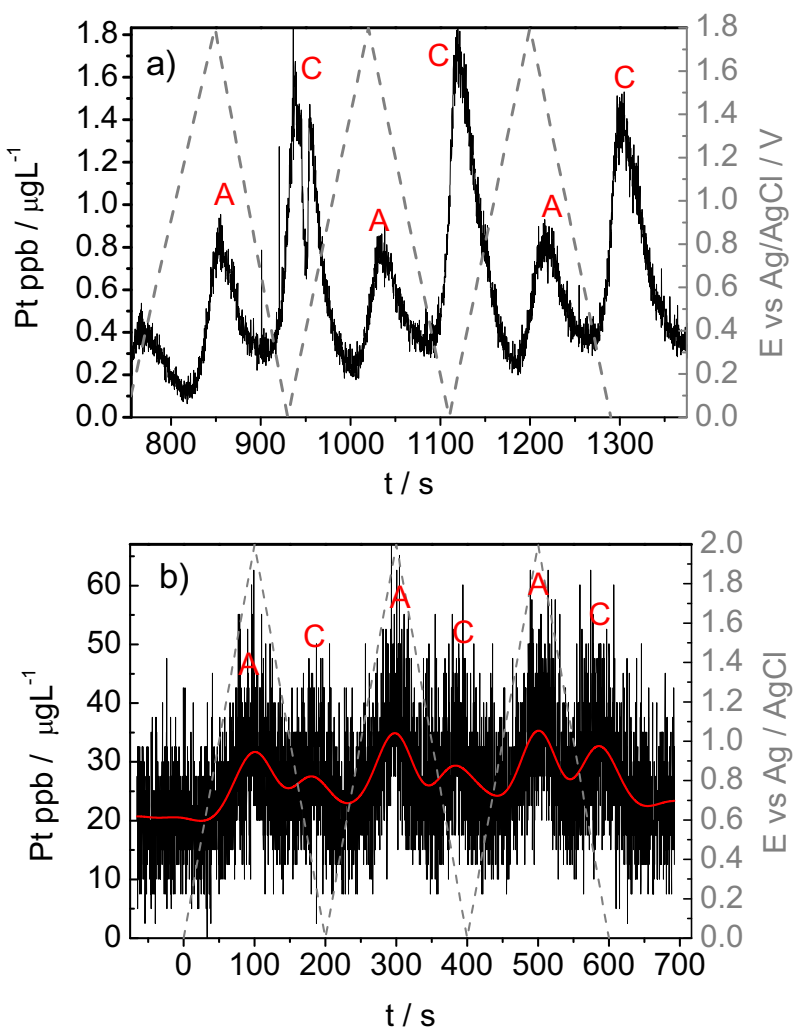

Fig. 1 Pt dissolution profile under potentiodynamic conditions in a aqueous and $\mathbf{b}$ methanol electrolyte $\left(0.1 \mathrm{M} \mathrm{NH}_{4} \mathrm{NO}_{3}\right)$ with a scan rate of $20 \mathrm{mVs}^{-1}$. Fourier transformation was used to smooth the raw ICP-MS signal namely 5.44 for water and 5.23 for methanol. This weak acidity is a consequence of $\mathrm{NH}_{4}{ }^{+}$cation salt with pKa 9.24. Unfortunately, no clearly resolved $\mathrm{Pt}$ dissolution could be observed till the upper potential limit (UPL) of $2 \mathrm{~V}$ vs. $\mathrm{Ag} / \mathrm{AgCl}$. This could be attributed to the lower sensitivity of the ICP-MS when methanol is introduced into plasma. Further experimental conditions and discussion regarding $\mathrm{pH}$ and reference electrode can be found in section $\mathrm{S} 1$ and S3 in Supplementary Information. As in case of Pt, Au electrochemical dissolution is transient in nature, meaning that it consists of anodic and cathodic counterparts (Fig. 2 and S1.3). ${ }^{3,24,36,37}$ Both dissolution counterparts are clearly resolved when cycling to $1.8 \mathrm{~V}$ vs. $\mathrm{Ag} / \mathrm{AgCl}$ in aqueous electrolyte (Fig. 2a). The anodic dissolution peak (labeled as A) and dominating cathodic dissolution peak (labeled as C) are observed. As noticed in the Pt case (Fig. 1b), Au dissolution trend is reversed as well, and anodic dissolution is predominant in the methanol medium (Fig. $2 \mathrm{~b}$ and Fig. S2).

\section{DISCUSSION}

Two obvious differences are observed when Pt dissolution in aqueous and methanol based electrolytes are compared. Namely, (i) the dissolution trend is altered, meaning that anodic dissolution is dominating over cathodic counterpart in the methanol. And (ii), the overall dissolution is much more intense in methanol. The observation under (i) should be explained as follows. As mentioned above anodic and cathodic dissolution are governed by (anodic) oxide formation and (cathodic) oxide reduction in aqueous electrolytes. This process is referred to as the oxide induced dissolution. ${ }^{23}$ Hence an alteration of dissolution should be ascribed to any possible interference with the chemistry of surface oxide formation as in the case of addition of chlorides
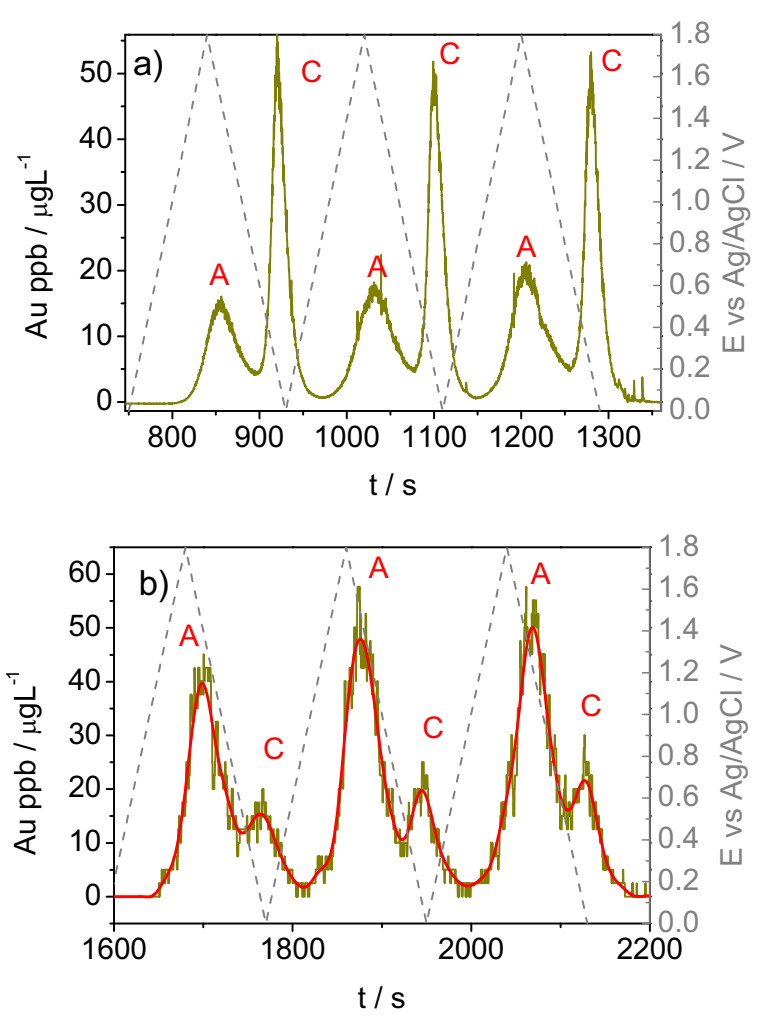

Fig. 2 Au dissolution profile under potentiodynamic conditions in a water-based and $\mathbf{b}$ methanol based electrolyte $\left(0.1 \mathrm{M} \mathrm{NH}_{4} \mathrm{NO}_{3}\right)$ with a scan rate of $20 \mathrm{mVs}^{-1}$. Fourier transformation was used to smooth the raw ICP-MS signal 
where Pt-oxide passivation is retarded. ${ }^{7}$ Since in methanol anodic dissolution is more intense in comparison to cathodic counterpart, it is safe to assume that the amount of oxide is rather small (Fig. $2 b)$. This is in line with the fact that in methanol Pt oxidates to a lesser degree since it is energetically more difficult to separate oxygen from $\mathrm{MeOH}$ then $\mathrm{H}_{2} \mathrm{O}$. In addition, the presence of trace amounts of water should not be neglected since it could affect the shape of the dissolution profile and partial formation of Pt oxide. ${ }^{38}$ The latter will be examined in further studies with an emphasis on minimizing the amount of water in an organic electrolyte. Nevertheless, we can safely assume that direct dissolution of $\mathrm{Pt}$ $\left(\mathrm{Pt} \rightarrow \mathrm{Pt}^{2+}\right)$ is the dominating anodic dissolution mechanism in the methanol experiment. This is in agreement with observation (ii). Namely, since the formation of $\mathrm{Pt}$ oxide is limited and the passivation of $\mathrm{Pt}$ surface is retarded $\mathrm{Pt}$ gets more prone to dissolution. A similar explanation as before should follow for $\mathrm{Au}$ dissolution trend when the two electrolytes are compared; due to the much lower amount of surface oxides, Au surface is less passivated and $\mathrm{Au}$ is therefore predominantly dissolving through direct dissolution mechanism $\left(\mathrm{Au} \rightarrow \mathrm{Au}^{3+}\right)$. By nature, $\mathrm{Au}$ oxide passivation ability is not as efficient as in the case of $\mathrm{Pt}$, and is therefore, enabling more direct dissolution at high potentials, i.e., oxygen evolution reaction region. ${ }^{24}$ This is also the reason that more $\mathrm{Au}$ is dissolving compared to Pt. The lower extent of passivation in methanol explains the enhanced anodic dissolution for both metals in comparison to the aqueous case.

We report, never before measured, time- and potential-resolved electrochemical dissolution of $\mathrm{Pt}$ and $\mathrm{Au}$ in the pure organic electrolyte and compared it to the well-studied aqueous electrolyte. By adapting the ICP-MS experimental setup for organic matrices, we were able to conclude two facts: (1) Pt and Au exhibit mostly direct anodic dissolution mechanism and (2) cathodic oxide-assisted pathway is hindered in organic media. Our modified EFC-ICP-MS analytical methodology is opening up many new possibilities for studying in situ corrosion behavior of metals in organic-based media, which are becoming of high interest in the fields of batteries, electrosynthesis, electrodeposition, electrocatalysis, and recycling.

\section{METHODS}

The setup in which an EFC is coupled to ICP-MS was already introduced in our previous publications. ${ }^{6-11}$ Shortly, a commercial BASi EFC (Cross-Flow Cell Kit MW-5052) with a homemade silicon gasket of a $1 \mathrm{~mm}$ thickness was coupled to an Agilent 7500ce ICP-MS instrument (Agilent Technologies, Palo Alto, USA) equipped with a MicroMist glass concentric nebulizer and a Peltier-cooled Scott-type double-pass quartz spray chamber. A forward radio frequency power of $1500 \mathrm{~W}$ was used with $\mathrm{Ar}$ gas flows: carrier $0.85 \mathrm{~L}$ per min, makeup $0.28 \mathrm{~L}$ per min, plasma $1 \mathrm{~L}$ per min, and cooling $15 \mathrm{~L}$ per min. $\mathrm{NH}_{4} \mathrm{NO}_{3}$ aqueous solution of $0.1 \mathrm{~mol} / \mathrm{L}(\mathrm{pH} 5.44$ ) was used as the electrolyte carrier medium. Solutions were pumped at $300 \mu \mathrm{L}$ per min using a syringe pump (World Precision Instruments-WPI sp100i). Platinum and gold polycrystalline disks $(d=3 \mathrm{~mm})$ were used as working electrodes and $\mathrm{Ag} / \mathrm{AgCl}$ (aqueous) BASi as a reference electrode. The electrochemical and ICP-MS dissolution signals were synchronized (Supplementary Information section S1 and Figure S1.1). According to the threefold signal to noise ratio $(\mathrm{S} / \mathrm{N})$, limit of detection was estimated to be 0.04 p.p.b. (Au) and 0.2 p.p.b. (Pt) for aqueous and 1 p.p.b. for ( $\mathrm{Au}$ ) and $>60$ p.p.b. (Pt) for the organic electrolyte. This means our Pt dissolution signal in organic media is below the limit of detection. Therefore, quantitative analysis is not possible. However, it can be still used in a qualitatively way to assess the changes of the dissolution profile features like clear differences between anodic and cathodic dissolution.

\section{Aqueous electrolyte}

Experimental procedure enclosed consecutive cycling from $0.0 \mathrm{~V}$ to different UPLs starting at $0.9 \mathrm{~V}$ and increasing by $0.1 \mathrm{~V}$ till $1.8 \mathrm{~V}$ vs. Ag/ $\mathrm{AgCl} .20 \mathrm{mV}$ per s was the chosen scan rate. At each potential excursion, three cycles were recorded.
Organic electrolyte

In the case of organic matrice, $0.1 \mathrm{M} \mathrm{NH}_{4} \mathrm{NO}_{3}$ solution in methanol (CHROMASOLV for high-performance liquid chromatography; SigmaAldrich, CAS: 67-56-1, water content according to Karl Fischer $=$ max. $0.0005 \%$ ) was chosen as the supporting electrolyte. In comparison to aqueous electrolyte, several instrumental modifications of the ICP interphase were done in order to perform the analysis.

Experimental procedure has been performed by consecutive cycling from $0.0 \mathrm{~V}$ to different UPLs starting at $0.9 \mathrm{~V}$ and increasing by $0.1-1.8 \mathrm{~V}$ (in the case of $\mathrm{Au}$ ) and $2 \mathrm{~V}$ (in the case of $\mathrm{Pt}$ ) $\mathrm{vs}$. $\mathrm{Ag} / \mathrm{AgCl}$. $20 \mathrm{mV}$ per s was the chosen scan rate. At each potential excursion, three cycles were recorded.

Data availability

The data that support the findings of this study are available from the corresponding author upon reasonable request.

\section{ACKNOWLEDGEMENTS}

This study was supported by the Slovenian Research Agency for the research programme P2-0034, P2-0152, and project Z2-8161.

\section{AUTHOR CONTRIBUTIONS}

The manuscript was written through contributions of all authors. All authors have given approval to the final version of the manuscript.

\section{ADDITIONAL INFORMATION}

Supplementary information accompanies the paper on the npj Materials Degradation website (https://doi.org/10.1038/s41529-018-0031-8).

Competing interests: The authors declare no competing interests.

Publisher's note: Springer Nature remains neutral with regard to jurisdictional claims in published maps and institutional affiliations.

\section{REFERENCES}

1. Koch, G. H., Brongers, M. P. H., Thompson, N. G., Virmani, Y. P. \& Payer, J. H. Corrosion costs and preventive strategies in the United States. Federal Highway Administration 1-12 (2002).

2. Klemm, S. O., Topalov, A. A., Laska, C. A. \& Mayrhofer, K. J. J. Coupling of a high throughput microelectrochemical cell with online multielemental trace analysis by ICP-MS. Electrochem. Commun. 13, 1533-1535 (2011).

3. Cherevko, S., Topalov, A. A., Zeradjanin, A. R., Katsounaros, I. \& Mayrhofer, K. J. J. Gold dissolution: towards understanding of noble metal corrosion. RSC Adv. 3, 16516 (2013).

4. Cherevko, S. et al. Dissolution of noble metals during oxygen evolution in acidic media. ChemCatChem 6, 2219-2223 (2014).

5. Xing, L., Jerkiewicz, G. \& Beauchemin, D. Ion exchange chromatography coupled to inductively coupled plasma mass spectrometry for the study of Pt electrodissolution. Anal. Chim. Acta 785, 16-21 (2013).

6. Jovanovič, P. et al. New insight into platinum dissolution from nanoparticulate platinum-based electrocatalysts using highly sensitive in situ concentration measurements. ChemCatChem 6, 449-453 (2014).

7. Pavlišič, A. et al. The influence of chloride impurities on $\mathrm{Pt} / \mathrm{C}$ fuel cell catalyst corrosion. Chem. Commun. 50, 3732-3734 (2014).

8. Jovanovič, P. et al. Potentiodynamic dissolution study of PtRu/C electrocatalyst in the presence of methanol. Electrochim. Acta 211, 851-859 (2016).

9. Hodnik, N. et al. New insights into corrosion of ruthenium and ruthenium oxide nanoparticles in acidic media. J. Phys. Chem. C 119, 10140-10147 (2015).

10. Jovanovič, P. et al. Electrochemical in-situ dissolution study of structurally ordered, disordered and gold doped PtCu3 nanoparticles on carbon composites. J. Power Sources 327, 675-680 (2016).

11. Gatalo, M. et al. Positive effect of surface doping with Au on the stability of Ptbased electrocatalysts. ACS Catal. 6, 1630-1634 (2016).

12. Lopes, P. P. et al. Relationships between atomic level surface structure and stability/activity of platinum surface atoms in aqueous environments. ACS Catal. 6, 2536-2544 (2016).

13. Lopes, P. P. et al. Dynamics of electrochemical Pt dissolution at atomic and molecular levels. J. Electroanal. Chem. (2017). 
14. Spanos, I. et al. Standardized benchmarking of water splitting catalysts in a combined electrochemical flow cell/inductively coupled plasma-optical emission spectrometry (ICP-OES) setup. ACS Catal. 7, 3768-3778 (2017).

15. Shrestha, B. R., Yadav, A. P., Nishikata, A. \& Tsuru, T. Application of channel flow double electrode to the study on platinum dissolution during potential cycling in sulfuric acid solution. Electrochim. Acta 56, 9714-9720 (2011).

16. Hodnik, N. et al. Platinum recycling going green via induced surface potential alteration enabling fast and efficient dissolution. Nat. Commun. 7, 13164 (2016).

17. Doidge, E. D. et al. A simple primary amide for the selective recovery of gold from secondary resources. Angew. Chem. Int. Ed. Engl. 55, 12436-12439 (2016).

18. Gerstl, M., Joksch, M. \& Fafilek, G. The dissolution of palladium as a function of glucose concentration in chloride containing solutions of acidic pH. J. Electroanal. Chem. 741, 1-7 (2015).

19. Papaiconomou, N., Glandut, N., Billard, I. \& Chainet, E. Unusual electrochemical behaviour of $\mathrm{AuBr} 4$ - in ionic liquids. Towards a simple recovery of gold(iii) after extraction into an ionic liquid. RSC Adv. 4, 58910-58915 (2014).

20. Papaiconomou, N., Cointeaux, L., Chainet, E., lojoiu, C. \& Billard, I. Uncertainty principle in the elucidation of the extraction mechanism of ions from aqueous towards ionic liquid phases. $\mathrm{PtCl}_{6}{ }^{2-}$ and $\left[\mathrm{C}_{1} \mathrm{C}_{8} \mathrm{IM}\right]\left[\mathrm{NTf}_{2}\right]$ as a textbook case. ChemistrySelect 1, 3892-3900 (2016).

21. Boorn, A. W. \& Browner, R. F. Effects of organic solvents in inductively coupled plasma atomic emission spectrometry. Anal. Chem. 54, 1402-1410 (1992).

22. Topalov, A. A. et al. Towards a comprehensive understanding of platinum dissolution in acidic media. Chem. Sci. 5, 631-638 (2014).

23. Topalov, A. A. et al. Dissolution of platinum: limits for the deployment of electrochemical energy conversion? Angew. Chem. Int. Ed. Engl. 51, 12613-12615 (2012).

24. Cherevko, S., Zeradjanin, A. R., Keeley, G. P. \& Mayrhofer, K. J. J. A comparative study on gold and platinum dissolution in acidic and alkaline media. J. Electrochem. Soc. 161, H822-H830 (2014).

25. Cherevko, S. et al. Dissolution of platinum in the operational range of fuel cells. ChemElectroChem 2, 1471-1478 (2015).

26. Polymeros, G. et al. High temperature stability study of carbon supported high surface area catalysts-expanding the boundaries of ex-situ diagnostics. Electrochim. Acta 211, 744-753 (2016).

27. Baldizzone, C. et al. Stability of dealloyed porous Pt/Ni nanoparticles. ACS Catal. $\mathbf{5}$, 5000-5007 (2015).

28. Keeley, G. P., Cherevko, S. \& Mayrhofer, K. J. J. The stability challenge on the pathway to low and ultra-low platinum loading for oxygen reduction in fuel cells. ChemElectroChem 3, 51-54 (2016).
29. Cherevko, S., Kulyk, N. \& Mayrhofer, K. J. J. Durability of platinum-based fuel cell electrocatalysts: dissolution of bulk and nanoscale platinum. Nano Energy 29, 1-14 (2016)

30. Jerkiewicz, G., Vatankhah, G., Lessard, J., Soriaga, M. P. \& Park, Y.-S. Surface-oxide growth at platinum electrodes in aqueous $\mathrm{H} 2 \mathrm{SO}$. Electrochim. Acta 49, 1451-1459 (2004).

31. $\mathrm{Yu}, \mathrm{K}$. et al. Degradation mechanisms of platinum nanoparticle catalysts in proton exchange membrane fuel cells: the role of particle size. Chem. Mater. 26, 5540-5548 (2014)

32. Yano, H., Watanabe, M., liyama, A. \& Uchida, H. Particle-size effect of Pt cathode catalysts on durability in fuel cells. Nano Energy 29, 1-11 (2016).

33. Topalov, A. A., Zeradjanin, A. R., Cherevko, S. \& Mayrhofer, K. J. J. The impact of dissolved reactive gases on platinum dissolution in acidic media. Electrochem. Commun. 40, 49-53 (2014).

34. Bindra, P. Platinum dissolution in concentrated phosphoric acid. J. Electrochem. Soc. 126, 1631 (1979).

35. Silverstein, T. P. \& Heller, S. T. P. K. A. Values in the undergraduate curriculum: what is the real pKa of water? J. Chem. Educ. 94, 690-695 (2017).

36. Cherevko, S., Topalov, AA, Katsounaros, I. \& Mayrhofer, K. J. J. J. Electrochemical dissolution of gold in acidic medium. Electrochem. Commun. 28, 44-46 (2013).

37. Kasian, O. et al. Electrochemical dissolution of gold in presence of chloride and bromide traces studied by on-line electrochemical inductively coupled plasma mass spectrometry. Electrochim. Acta 222, 1056-1063 (2016).

38. Staszak-Jirkovský, J. et al. Water as a promoter and catalyst for dioxygen electrochemistry in aqueous and organic media. ACS Catal. 5, 6600-6607 (2015).

Open Access This article is licensed under a Creative Commons Attribution 4.0 International License, which permits use, sharing, adaptation, distribution and reproduction in any medium or format, as long as you give appropriate credit to the original author(s) and the source, provide a link to the Creative Commons license, and indicate if changes were made. The images or other third party material in this article are included in the article's Creative Commons license, unless indicated otherwise in a credit line to the material. If material is not included in the article's Creative Commons license and your intended use is not permitted by statutory regulation or exceeds the permitted use, you will need to obtain permission directly from the copyright holder. To view a copy of this license, visit http://creativecommons. org/licenses/by/4.0/.

(c) The Author(s) 2018 